\title{
Anodic stripping voltammetry of silver in the absence of electrolytes: theory and experiment
}

\author{
Kamonwad Ngamchuea, Christopher Batchelor-McAuley*, Richard G. Compton* \\ *Corresponding authors:
}

Christopher Batchelor-McAuley, Department of Chemistry, Physical \& Theoretical Chemistry Laboratory, University of Oxford, South Parks Road, Oxford, OX1 3QZ, United Kingdom. Email: christopher.batchelor-mcauley@chem.ox.ac.uk. Tel: +44(0)1865275448

Richard G. Compton, Department of Chemistry, Physical \& Theoretical Chemistry Laboratory, University of Oxford, South Parks Road, Oxford, OX1 3QZ, United Kingdom. Email: richard.compton@ chem.ox.ac.uk. Tel: +44(0)1865275957 Fax: +44(0)1865275410

\begin{abstract}
This work demonstrates that anodic stripping voltammetry at a microdisc electrode allows the detection of silver in the absence of added supporting electrolyte. The voltammetry however becomes distorted under low-support conditions. A semi-analytical model is developed to investigate the effects of the lack of supporting electrolyte on the voltammetric responses. First, the alteration in the double-layer kinetics is studied. In particular, we show that the classical Frumkin correction cannot explain the distorted shape of the voltammetry and only accounts for no more than $\sim 50 \%$ of the shift in the voltammetric peaks. Second, compared to the Frumkin correction, Ohmic drop contributes much more significantly to the shift in the peak potential and the distorted wave shape upon lowering electrolyte concentrations. The Ohmic drop determined on the basis of predicted constriction resistance as expressed by Newman gives a reasonable approximation to the solution resistances, especially at ionic strengths above $200 \mu \mathrm{M}$. In deionized water or ultra-low conductivity water with the ionic strength of sub-micromolar level, a discrepancy in the resistances of up to a factor of 25 was observed. This discrepancy likely arises due to the assumptions made in applying the
\end{abstract}


Newman model to the experimental system. Finally, we show that a model which considers simultaneously the electrode kinetics and the ohmic drop effects give a consistent fit with experimental data, when the values of the resistances are appropriately adjusted to account for the inaccuracy in the approximation of constriction resistances.

\section{Keywords}

Voltammetry; Low ionic strength; Frumkin correction; Electron tunnelling; Ohmic drop

\section{Introduction}

Anodic stripping voltammetry has been widely employed in the characterization of metals and metal nanoparticles, as well as in the analytical detection of metal ions in solutions. ${ }^{1-6}$ The technique involves the deposition of metal onto an electrode surface, either by electrochemical reduction or non-electrochemical immobilization, and the subsequent oxidative 'stripping' of the metal from the surface. Both the deposition and stripping processes have been well-investigated and widely conducted in the presence of a relatively large quantity of inert supporting electrolytes. ${ }^{1-9}$ Typically support ratios of ca. 30 for steadystate $^{10}$ and 100 for transient ${ }^{11}$ (e.g. cyclic voltammetry) measurements are required to ensure the mass-transport can be considered a diffusion only problem. ${ }^{1-5,11}$ In the absence or at low electrolyte concentrations, significant distortion of the voltammogram is inevitable due to ohmic drop and the significant alteration in the electrical double layer structure. ${ }^{11-14}$ The use of supporting electrolytes however may be found to be unsuitable in some analytical applications such as in work involving biological or some environmental samples. This requirement for electrolytic support can be significantly relaxed by using an electrode with microscopic dimensions, where only relatively low currents are passed allowing practical measurements without additional supporting electrolyte. ${ }^{12,15-19}$ 
In this work, we demonstrate that the oxidative electrochemical dissolution of silver can take place at a microdisc electrode in the (near) absence of electrolyte i.e. without the addition of salts. The ions, as low as sub-micromolar, naturally present in deionized water due to the dissociation of water and dissolved atmospheric carbon dioxide are sufficient for the oxidation process to take place. The experimentally observed voltammograms in the absence of electrolytes however differ from that under the full support conditions. This work thus develops a semi-analytical model for the interpretation of the stripping voltammetry at a microdisc electrode at a range of electrolyte concentrations.

Considering first the effects of lowering electrolyte concentrations on the electrode kinetics, there are three components included in this model: $i$ ) the structure and composition of the double layer, ii) double-layer electrode kinetic effects (Frumkin correction ${ }^{13}$ ), and iii) extended electron transfer. The Gouy-Chapman-Stern model is used to describe the structure and composition of the double layer in this work; other models are also considered in the Theory section. The relation between the electrical double layer and the electrode kinetics (Butler-Volmer) is then described by the Frumkin correction. ${ }^{13}$ This theoretical model was first proposed by Frumkin in 1933 to explain the effects of the altered double layer on the kinetics of hydrogen evolution. ${ }^{13}$ Further experimental electrochemical evidences however are relatively few. This work uses silver oxidation as an example to investigate whether the classical Frumkin correction can describe the distortion in the stripping voltammograms observed at low electrolyte concentrations. Herein, the Frumkin model is combined into the Butler-Volmer equation allowing the influence of the back reaction $\left(\mathrm{Ag}^{+}+\mathrm{e}^{-} \leftrightarrows \mathrm{Ag}\right.$; 'quasireversible' electron transfer) to be accounted for, as well as the effects of electron tunnelling over a range of distances ('extended' electron tunnelling). 
In addition to the kinetic effects, the low ionic strength of the electrolyte can give rise to an electric field arising due to the occurrence of the redox reaction. The extent of and magnitude of the field is dependent upon the relative abundance of the electroactive and electroinactive ionic species. The electrical conductivity of the solution decreases with electrolyte concentrations causing a larger 'ohmic drop' through the solution phase, thus decreasing the potential difference experienced by the redox active group at the electrode surface. Moreover, the presence of the field can alter the mass transport characteristics of the system through 'migration' of charged species. These two phenomena although different are mutually related; however only the former effect will be considered in this paper. This approximation is relatively valid in this case due to the electroactive reactant being neutral. The full mathematical descriptions of the non-uniform electric field and migration (Nernst-PlanckPoisson equations) have been previously reported for both steady-state ${ }^{10,20}$ and transient limits, ${ }^{11,21-22}$ and will not be explicitly performed herein. Instead, a semi-analytical approach is taken to study the ohmic drop effect by approximating the resistance of the solution to be concentrated in the vicinity of the electrode. The resistance of the solution between a small disc electrode (working electrode) and a large (counter) electrode at a long distance away may be estimated from knowledge of the solution electrical conductivity, as measured experimentally, using an equation derived by Newman ${ }^{23}$ (equation 26). However, we note in the present model the possible influence of convection is not accounted for. ${ }^{24}$

Both kinetic and ohmic drop effects are combined into the final theoretical model. Comparison is then drawn between the theoretical model and experimental data for the system of silver stripping at a microdisc electrode at a range of supporting electrolyte concentrations.

\section{Theory}


This work considers a 1-electron metal oxidation process:

$$
\mathrm{M}(\mathrm{s}) \rightarrow \mathrm{M}^{+}(\mathrm{aq})+\mathrm{e}^{-}(\text {metal })
$$

and the effects of the lack of supporting electrolyte on the voltammetric response.

Predominantly, metal oxidation has been investigated under full-support conditions. ${ }^{3-5}$ Under these conditions, a compressed electrical double layer is formed and the redox species - at distances appropriate for electron tunnelling - are completely screened from the electric field generated at the electrode. At the distance of only a few nanometers away from the interface, the electric field becomes negligible and the solution-phase mass transport is exclusively via diffusion. It is also commonly assumed that the conductivity of the electrolyte solution is sufficiently high such that any Ohmic drop has negligible effects on the measured electrochemical responses.

In the presence of insufficient supporting electrolytes or 'low-support', the effects of electric fields become significant. An electric field may arise either due to the capacitative charging of the electrode itself or due to the injection or removal of charge from the solution as a result of a redox process being driven at the interface. Redox species within the proximity of electrode, where electron tunnelling can occur, experience the field. The altered energy of the redox species due to the electric field can have an effect on the electrode kinetics and hence the resulting electrochemical responses, as discussed below. The effects of increased resistances at low concentrations of electrolytes, or ohmic drop, are further considered.

\subsection{Reversible electron transfer kinetics for stripping voltammetry at a microdisc electrode}

Assuming the electrode kinetics are infinitely fast, the surface concentrations of $\mathrm{M}^{+}$ions can be described by the Nernst equation: 


$$
E=E_{\mathrm{f}}^{\Theta}+\frac{R T}{F} \ln \frac{\left[\mathrm{M}^{+}\right]_{0}}{[]^{\Theta}}
$$

Equation 2 can be rearranged to:

$$
\left[\mathrm{M}^{+}\right]_{0}=[]^{\Theta} \exp \left(\frac{F}{R T}\left(E-E_{\mathrm{f}}^{\Theta}\right)\right)
$$

where $E$ is the electrode potential, $E_{\mathrm{f}}^{\Theta}$ is the formal potential. $R, T$ and $F$ are the molar gas constant $\left(8.314 \mathrm{~J} \mathrm{~K}^{-1} \mathrm{~mol}^{-1}\right)$, absolute temperature (in $\mathrm{K}$ ) and the Faraday constant (96485 C mol $^{-1}$ ) respectively. $\left[\mathrm{M}^{+}\right]_{0}$ is the concentration of $\mathrm{M}^{+}$at the surface of the electrode (or more precisely at the plane of closest approach). [ $]^{\Theta}$ is the standard state $\left(1 \mathrm{~mol} \mathrm{dm}^{-3}\right)$. Note in this work the thermodynamics of the silver stripping process are not considered to be altered by the presence of the supporting electrode, for the case in which less than a monolayer of material is being removed from a substrate this approximation is not strictly valid however in the present work we consider the removal of multiple layers of deposited material.

In linear-sweep voltammetry, the potential is varied linearly as a function of time $(t)$ :

$$
E_{\text {app }}=E_{\mathrm{i}}+v t
$$

where $E_{\text {app }}$ is the applied potential, $E_{\mathrm{i}}$ is the initial potential and $v$ is the scan rate. Without the consideration of ohmic drop in this section, the electrode potentials $(E)$ used in the Nernst equation have the same values as $E_{\text {app }}$.

For infinitely fast electrode kinetics, the oxidative flux is limited by the rate of mass transport of $\mathrm{M}^{+}$(aq) away from the electrode. The mass transport limited flux $(j)$ is given by:

$$
j=-k_{\mathrm{MT}}\left[\mathrm{M}^{+}\right]_{0}
$$


where $k_{\mathrm{MT}}$ is the mass transport coefficient. At a microdisc electrode, under an assumption that the electrode can be approximated as being uniformly accessible, $k_{\mathrm{MT}}$ can be expressed as:

$$
\begin{gathered}
k_{\mathrm{MT}}=\frac{D}{\delta} \\
\delta=\frac{\pi r_{\mathrm{e}}}{4}
\end{gathered}
$$

where $D$ is the diffusion coefficient $\left(\mathrm{m}^{2} \mathrm{~s}^{-1}\right)$ of $\mathrm{M}^{+} . \delta$ is the diffusion layer thickness and $r_{\mathrm{e}}$ is the radius of the microdisc electrode. Hence this model is strictly only valid for a hemispherical electrode but under the steady-state regime we can justifiably apply this approximation. This value of $k_{\mathrm{MT}}$ is based on the assumption that the mass transport (diffusion) of $\mathrm{M}^{+}$away from the microdisc electrode is under the steady-state divergent diffusion regime. This is strictly true for the long-time limit, where $t>r_{\mathrm{e}}{ }^{2} / D$.

The mass transport limited current $(I)$ is given by

$$
I=-n F A j
$$

where $n$ is the number of electron transfer ( $n=1$ in this case). $A$ is the geometric area of the electrode surface.

The total amount of charge $(Q)$ passed between the start of the voltammetric scan and the time $t$ is determined by

$$
Q=\int I \mathrm{~d} t
$$

In anodic stripping voltammetry, there is a finite amount of starting material on the surface of the electrode. After all of the surface-deposited metal has been oxidized, $Q$ reaches a 
maximum value of $Q_{\max }$. Beyond that, the oxidative currents return to zero $(I=0)$. Figure 1 gives examples of anodic stripping voltammetry predicted for different amount of starting material deposited on the electrode. The peak potential $\left(E_{\mathrm{p}}\right)$ shifts to higher (more positive) potentials as the amount of the deposited metal increases.

From the model described above, the oxidative currents would only be sensitive to the concentrations of the electroactive species (Nernst equation); however, the influence of the supporting electrolyte concentration has not been considered.

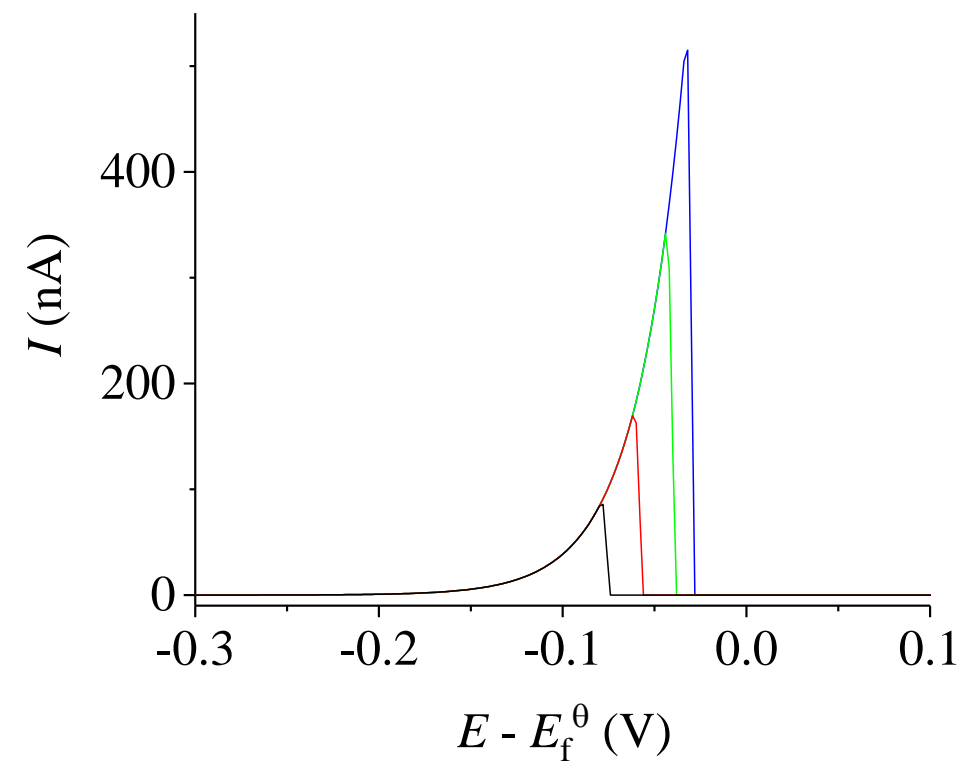

Figure 1: Theoretically predicted anodic stripping voltammetry of a one-electron metal oxidation in the reversible limit for different amounts of starting material: (black) $125 \mathrm{nmol}$, (red) $250 \mathrm{nmol}$, (green) $500 \mathrm{nmol}$ and (blue) $750 \mathrm{nmol}$. Scan rate of $20 \mathrm{mV} \mathrm{s}^{-1} . E_{f}^{\Theta}=0.5 \mathrm{~V}, D=1 \times 10^{-9} \mathrm{~m}^{2} \mathrm{~s}^{-1}, r_{\mathrm{e}}=$ $10 \mu \mathrm{m}$.

2.2 Irreversible electron transfer kinetics for stripping voltammetry at a microdisc electrode 
In the irreversible limit, mass transport of $\mathrm{M}^{+}$away from the electrode is significantly faster than the electrode kinetics. The oxidative flux $(j)$ is controlled by the rate of electron transfer, described by the Butler-Volmer kinetics:

$$
j=K_{\mathrm{app}}[]^{\Theta} \exp \left(\frac{\beta F}{R T}\left(E-E_{f}^{\Theta}\right)\right)
$$

where $E$ is the electrode potential ( $E=E_{\text {app }}$ if ohmic drop is not included). $\beta$ is the charge transfer coefficient. $K_{\text {app }}$ is the apparent rate of electron transfer $\left(\mathrm{m} \mathrm{s}^{-1}\right)$, discussed below (eqn. 11).

At high overpotentials it may be important to consider the influence of Marcus type electron transfer kinetics but in the present work we restrict ourselves to considering the electron transfer rate to being well described by the Butler-Volmer formalism. Electron transfer between the electrode and a redox active group is driven by a potential difference. In the present case, if $\mathrm{M}$ (the metal atom) were to be considered as part of the bulk metal of the electrode, it would not experience any driving force for electrochemical reactions. Therefore to oxidize, $\mathrm{M}$ when at its transition state must at least partially physically extend into the double layer structure. Moreover, at this transition point the metal atom will also likely be partially solvated. The partial solvation of the metal and the requirement of the transition state being to some extent distant from the metal interface the double layer, allows the distinction between the phases of the electrode and $\mathrm{M}$, and suggests that the electrochemical driving force and hence the apparent rate of electron transfer may be approximated using the Frumkin-type correction, ${ }^{13}$ as described next. 


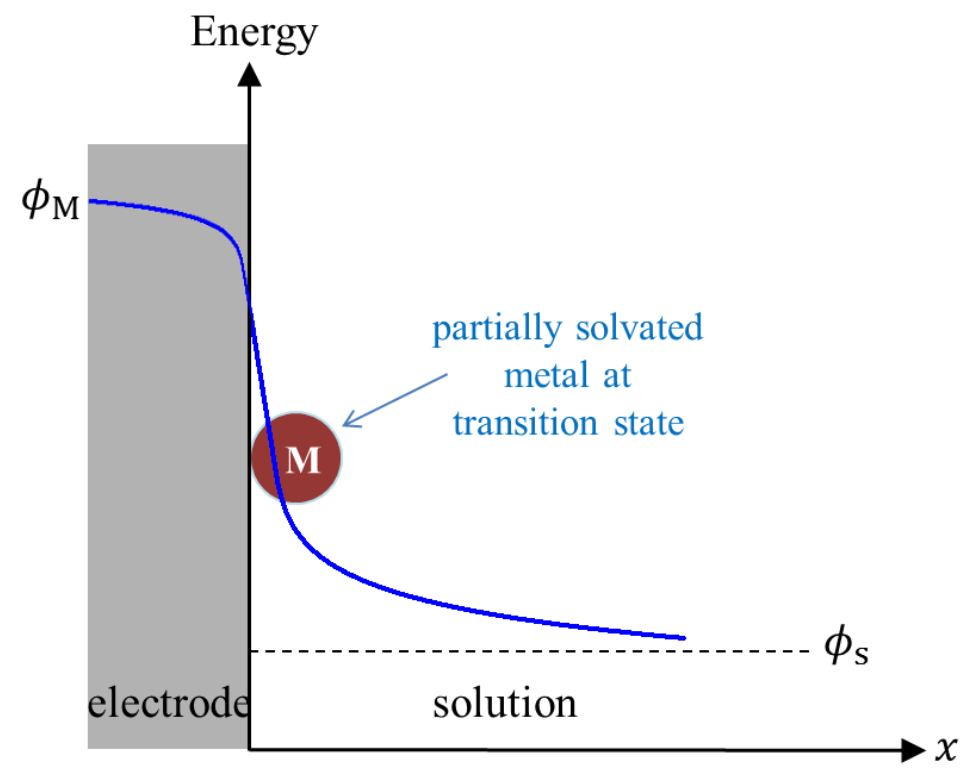

Figure 2: A schematic diagram showing the interface between electrolyte solution, electrode and a metal $\mathrm{M}$ deposited on the electrode. The potential of the electrode decreases slightly near the interface compared to the bulk electrode potential $\left(\phi_{\mathrm{M}}\right)$, as suggested by the Thomas-Fermi model of electron density distribution. ${ }^{25}$ The metal $\mathrm{M}$ is not part of the electrode, and experiences the potential drop intermediate between that of the electrode and the bulk solution $\left(\phi_{\mathrm{s}}\right)$. The approximate potential profile in this region is often predicted by the Gouy-Chapman or Gouy-Chapman-Stern models, described in text.

As first recognized by Frumkin ${ }^{13}$ in the system of proton reduction, the electrode kinetics can be influenced by the alteration in the double layer. $K_{\text {app }}$ is sensitive to the potentials experienced by the electroactive species at the point of electron transfer: ${ }^{26}$

$$
K_{\text {app }}=K^{0} \exp \left(\frac{-\left(z_{\mathrm{M}}+\beta\right) F}{R T}\left(\phi(x)-\phi_{\mathrm{s}}\right)\right)
$$

where $K^{0}$ is the standard rate constant $\left(\mathrm{m} \mathrm{s}^{-1}\right)$ at distance $x$ from the electrode; this parameter is discussed further in the 'tunnelling section' below. $z_{M}$ is the charge of metallic $M\left(z_{M}=0\right)$. $\phi(x)$ and $\phi_{s}$ are the potentials at distance $x$ and of the bulk solution respectively.

In this work, we determine the potential profile $\left(\phi(x)-\phi_{s}\right)$ according to the model which has been previously described ${ }^{27}$ and is also discussed briefly below. We then consider the 
effect of extended tunnelling on the effective standard rate constants ${ }^{28}$ and develop a model which investigates the interplay between the distance-dependent electron tunnelling and potential distribution, and the influence of these effects on the apparent rate of electron transfer. This section on the 'extended' Frumkin correction is included for completeness. Ultimately, as will be shown for the present experimental case, the rate of electrochemical reaction is seemingly insensitive to the double layer structure, likely reflecting the very high electrochemical rate constants of the process.

The potential experienced by the electroactive species $(\phi(x))$ is different from that applied to the working electrode (relative to the reference electrode). The variation of $\phi(x)$ as a function of applied potentials and distances may be described by the Helmholtz, GouyChapman or Gouy-Chapman-Stern models. Figure 3 schematically depicts the potentialdistance profiles predicted according to the three models.

In the Gouy-Chapman (GC) model, the distribution of charges is balanced by the electric force ('ordering') and thermal motion ('disordering'). The GC double layer, also known as the diffuse layer, for a 1:1 electrolyte can be described by the following potential distribution: ${ }^{26}$

$$
\left(\phi(x)-\phi_{\mathrm{s}}\right)=\frac{4 k_{\mathrm{B}} T}{z e} \tanh ^{-1}\left\{\left(\tanh \left(\frac{z e\left(\left(\phi_{\mathrm{M}}-\phi_{\mathrm{s}}\right)-\phi_{\mathrm{pzc}}\right)}{4 k_{\mathrm{B}} T}\right)\right) \exp \left(\frac{-c^{0.5} x}{3.04 \times 10^{-10}}\right)\right\}
$$

where $k_{\mathrm{B}}$ is the Boltzmann constant $\left(1.38 \times 10^{-23} \mathrm{~J} \mathrm{~K}^{-1}\right) . z$ is the charge of the electrolytic ions. $e$ is the elementary charge $\left(1.60 \times 10^{-19} \mathrm{C}\right) . \phi_{\mathrm{M}}$ and $\phi_{\mathrm{S}}$ are the potentials of the electrode and bulk solution respectively. $c$ is the concentration of the electrolyte and $\phi_{\mathrm{pzc}}$ is the potential of zero charge. This expression is correct for a double layer at a planar surface, 
in the case of small electrodes the possible curvature of the double layer structure may need to be explicitly accounted for.

The GC model however considers ions as point charges and does not take into account the size of the ions and their hydration shells. At a flat electrode surface, the maximum closepacked concentration of typical ions with radii $\sim 150 \mathrm{pm}$ is $\sim 60 \mathrm{M}$, see Section $\mathrm{S} 1.1$ (SI) for calculation detail. Figure S1.2 in the SI however demonstrate that the surface concentrations of ionic species predicted by the GC model can be several orders of magnitude higher than the maximum close-packed limits, especially at the potentials relevant to the oxidation of many metals, and as such is physically unrealistic.

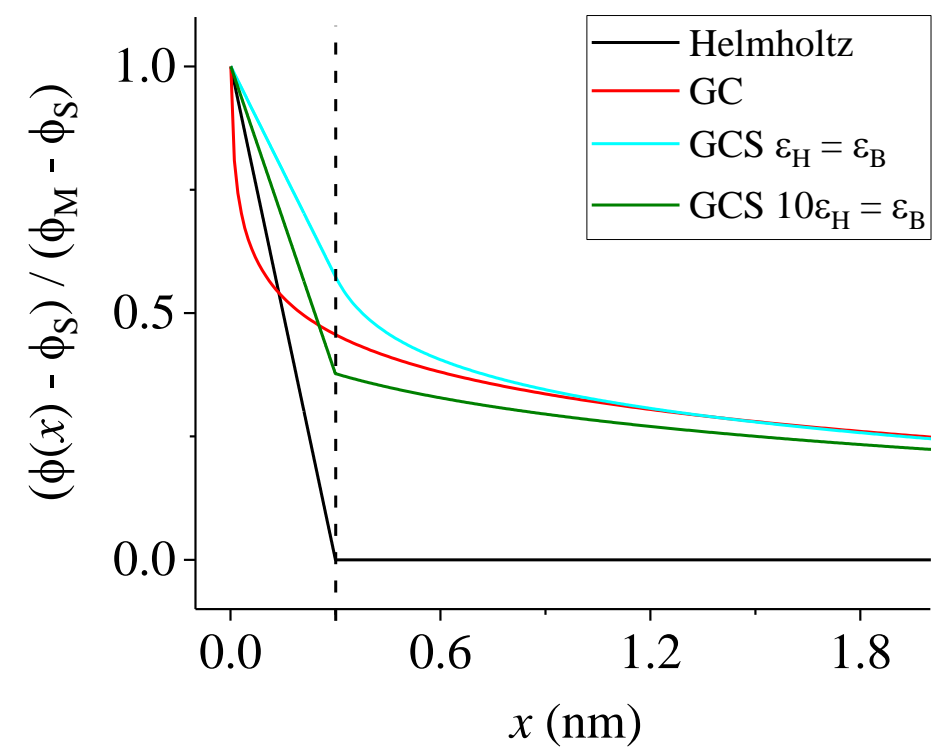

Figure 3: Potential profiles predicted according to the Helmholtz, Gouy-Chapman and GouyChapman-Stern $\left(\varepsilon_{\mathrm{H}}=\varepsilon_{\mathrm{B}}\right.$ and $10 \varepsilon_{\mathrm{H}}=\varepsilon_{\mathrm{B}}$, refer to text for detail) models for a 1:1 electrolyte of $1 \mathrm{mM}$ concentration at the applied potential of $0.5 \mathrm{~V}$.

The Gouy-Chapman-Stern (GCS) model combines the Helmholtz and the GC models in recognition that although thermal motion plays an important role, the strong electric field still dominates at distances very close to the electrode. In this region known as the Helmholtz 
layer $\left(x_{\mathrm{H}}\right.$, typically assumed to be comparable to the size of a water molecule i.e. $x_{\mathrm{H}}=3 \AA$ ), the potential is modelled as varying linearly across this region. Beyond that $(x>3 \AA)$, the charge is screened by solution phase ions which are subject to thermal motion. The potentials in the GCS double layer can be described by equations 13-14.

At $x \leq x_{\mathrm{H}}$

$$
\left(\phi(x)-\phi_{\mathrm{s}}\right)=\left(\phi_{\mathrm{M}}-\phi_{\mathrm{s}}\right)+x\left[\frac{\mathrm{d}\left(\phi(x)-\phi_{\mathrm{s}}\right)}{\mathrm{d} x}\right]_{x=x_{\mathrm{H}}}
$$

At $x \geq x_{\mathrm{H}}$

$$
\left(\phi(x)-\phi_{\mathrm{s}}\right)=\frac{4 k_{\mathrm{B}} T}{z e} \tanh ^{-1}\left\{\left(\tanh \left(\frac{z e\left(\left(\phi_{x=x_{\mathrm{H}}}-\phi_{\mathrm{s}}\right)-\phi_{\mathrm{pzc}}\right)}{4 k_{B} T}\right)\right) \exp \left(\frac{-c^{0.5}\left(x-x_{\mathrm{H}}\right)}{3.04 \times 10^{-10}}\right)\right\}
$$

The two models may be combined by setting the boundary conditions for the electric potential $(\phi)$ and electric displacement field $(\boldsymbol{D})$ to be continuous: ${ }^{29}$

$$
\begin{aligned}
& \boldsymbol{D}=\varepsilon \frac{\mathrm{d} \phi}{\mathrm{d} x} \\
& \left.\varepsilon_{\mathrm{H}} \frac{\mathrm{d} \phi_{\mathrm{H}}}{\mathrm{d} x}\right|_{x=x_{\mathrm{H}}}=\left.\varepsilon_{\mathrm{B}} \frac{\mathrm{d} \phi_{\mathrm{B}}}{\mathrm{d} x}\right|_{x=x_{\mathrm{H}}} \\
& \left.\phi_{\mathrm{H}}\right|_{x=x_{\mathrm{H}}}=\left.\phi_{\mathrm{B}}\right|_{x=x_{\mathrm{H}}}
\end{aligned}
$$

where the subscripts $\mathrm{H}$ and B refer to the Helmholtz layer and the bulk solvent respectively. The dielectric constant $(\varepsilon)$ in the Helmholtz layer is reportedly smaller than the bulk solvent by approximately an order of magnitude $\left(10 \varepsilon_{\mathrm{H}} \approx \varepsilon_{\mathrm{B}}\right),{ }^{30}$ the potentials thus drop faster in the 
inner Helmholtz layer but still less so than the GC model, see Figure 3. This model will be used throughout the rest of this work.

The potential-distance profiles theoretically predicted by the GCS model (with $10 \varepsilon_{\mathrm{H}} \approx \varepsilon_{\mathrm{B}}$ ) for different concentrations of electrolytes are given in Figure 4a. At lower electrolyte concentrations, $\phi(x)$ drops much more slowly with distances. As the driving force for the electrochemical reaction (as described by equations 10-11) is determined by the difference between $\phi_{M}$ and $\phi(x)$, the reaction rate will be sensitive to the position of the redox group away from the electrochemical interface. This distance dependency will also be highly sensitive to the supporting electrolyte concentration. This change in the electron transfer rate is reflected in $K_{\mathrm{app}}$, as presented in Figure $4 \mathrm{~b}$.
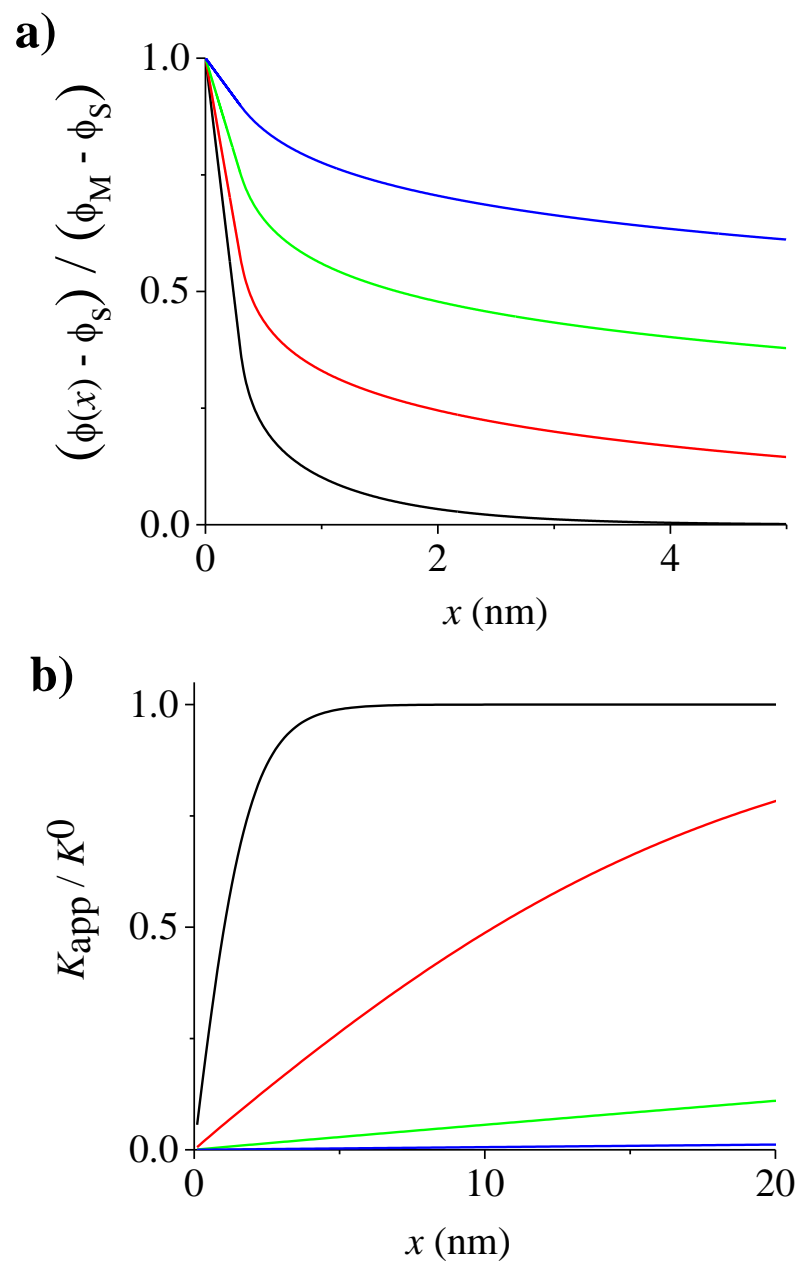
Figure 4: a) Variation in potentials $\left(\phi(x)-\phi_{\mathrm{s}}\right)$ and b) the apparent rate of electron transfer $\left(K_{\mathrm{app}}\right)$ as a function of distance from the electrode $(x)$ as predicted by the Gouy-Chapman-Stern model (with $x_{\mathrm{H}}$ $=0.3 \mathrm{~nm}$ and $10 \varepsilon_{\mathrm{H}}=\varepsilon_{\mathrm{B}}$ ) for different concentrations of 1:1 electrolytes: (black) $100 \mathrm{mM}$, (red) 1 $\mathrm{mM}$, (green) $10 \mu \mathrm{M}$ and (blue) $0.1 \mu \mathrm{M}$. These potential profiles are determined for $\phi_{\mathrm{M}}-\phi_{\mathrm{S}}=0.5 \mathrm{~V}$. Note that the variation in $\phi(x)$ is strongly dependent on $\phi_{\mathrm{M}}{ }^{27}$

Having determined the potential profiles, the effective standard rate constant (eqn. 11) is next considered. An electron is transferred between the electrode and the electroactive species via tunnelling. In many electrochemical theoretical models, the electron transfer is assumed, following Frumkin, to occur via tunnelling at a fixed plane. However, electrons tunnel over a range of distances (extended electron transfer) with the probability of the tunnelling falling exponentially with distance (eqn. 18). ${ }^{31}$ The inclusion of extended electron transfer into the electrochemical model has been demonstrated to have a significant effect on the theoretically predicted responses. ${ }^{28}$ The 'extended' electron transfer effectively reduces the Frumkin effect by allowing electron tunnelling at further distances outside of the double layer region. In this work, the effect of extended electron transfer is thus further studied. In particular, the balance between the decreased probability of electron tunnelling and the increased electrochemical rate as a function of distances is considered.

At a finite distance $x$ from the electrode surface,

$$
k^{0}=k^{\prime} \exp \left(-\beta_{\mathrm{t}} x\right)
$$

where $\beta_{\mathrm{t}}$ is a parameter that reflects the energy barrier height for tunnelling. $\beta_{\mathrm{t}}$ has the value of $1.59 \mathrm{~A}^{\mathrm{o}-1}$ for water. ${ }^{31} k^{\prime}\left(\mathrm{s}^{-1}\right)$ is the standard rate constant at $x=0 . k^{0}\left(\mathrm{~s}^{-1}\right)$ is the effective standard rate constant and is a function of distance $x$ from the electrode. Note that in this extended tunnelling model, we introduce a new parameter $k^{0}$ to refer to the effective standard 
rate constant, instead of using $K^{0}$ which has been introduced in equation 11 . The units of $k^{\prime}$ and $k^{0}$ are ' $\mathrm{s}^{-1}$,' different from $K^{0}$ which has the unit of ' $\mathrm{m} \mathrm{s}^{-1}$,' the origin of which is described next.

In the model of extended electron transfer in the irreversible kinetic limit, the oxidative flux is determined by:

$$
j=\int_{0}^{\infty} k_{\text {app }}[]^{\Theta} \exp \left(\frac{\beta F}{R T}\left(E-E_{f}^{\Theta}\right)\right) \mathrm{d} x
$$

where $k_{\text {app }}$ is related to $k^{0}$ in the same way that $K_{\text {app }}$ is related to $K^{0}$ according to equation 11. The integration of $k_{\text {app }}$ over a range of distances or $\int_{0}^{\infty} k_{\text {app }} \mathrm{d} x$ gives the effective standard rate constant which is equivalent to $K_{\text {app }}$, with the units of ' $\mathrm{m} \mathrm{s}^{-1}$.' This expression accounts for both the change in rate of the electrochemical reaction due to the influence of the tunnelling probability and the influence of the double layer upon the energies of charged redox species in the vicinity of the electrode. Figure 5 displays the voltammetric responses predicted by this model for different concentrations of supporting electrolytes. The value of $k^{\prime}$ of $100 \mathrm{~s}^{-1}$ in Figure 5 was chosen arbitrarily to give $\int_{0}^{\infty} k_{\text {app }} \mathrm{d} x\left(\mathrm{~m} \mathrm{~s}^{-1}\right)$ which is significantly smaller than the mass transport coefficient $\left(k_{\mathrm{MT}}=D / \delta\right)$. For example, $\int_{0}^{\infty} k_{\text {app }} \mathrm{d} x=6.1 \times 10^{-13} \mathrm{~m} \mathrm{~s}^{-1} v$ s. $k_{\mathrm{MT}}=1.3 \times 10^{-4} \mathrm{~m} \mathrm{~s}^{-1}$ for $D=1 \times 10^{-9} \mathrm{~m}^{2} \mathrm{~s}^{-1}$ and $r_{\mathrm{e}}=10 \mu \mathrm{m}$ in $100 \mathrm{mM}$ electrolyte solution. All other parameters are given in the caption of the figure and in Table 1. It is shown that the peak position shifts to more positive potentials at lower electrolyte concentrations, but the shape of the peak remains unchanged. 


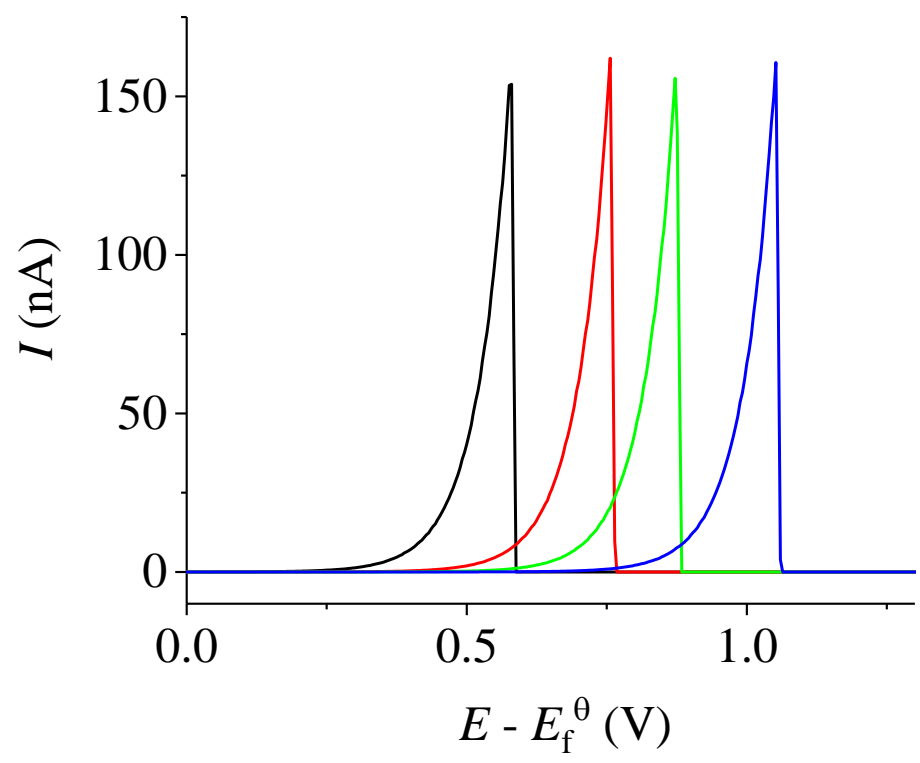

Figure 5: Theoretically predicted anodic stripping voltammetry of a one-electron metal oxidation in an irreversible limit with extended electron transfer in different concentrations of 1:1 electrolytes: (black) $100 \mathrm{mM}$, (red) $100 \mu \mathrm{M}$, (green) $1 \mu \mathrm{M}$ and (blue) $1 \mathrm{nM}$. Scan rate of $20 \mathrm{mV} \mathrm{s}^{-1} \cdot Q_{\max }=500$ $\mathrm{nC}, k^{\prime}=100 \mathrm{~s}^{-1}, \beta=0.5, E_{f}^{\Theta}=0.5 \mathrm{~V}, \phi_{\mathrm{pzc}}=0 \mathrm{~V}$.

\subsection{Quasi-reversible electron transfer for stripping voltammetry at a microdisc electrode}

Above, two extreme limits of electron transfer kinetics have been considered. In fact, the electrode kinetics is most often not indefinitely fast, but is also not sufficiently small for the back reaction to be completely neglected (as a result of mass transport of all the products away from the electrode). A more general model, as presented below, describes both limits.

The Butler-Volmer equation for electron transfer is given by:

$$
j=k_{\mathrm{ox}}[]^{\Theta} \exp \left(\frac{\beta F}{R T}\left(E-E_{f}^{\Theta}\right)\right)-k_{\text {red }}\left[\mathrm{M}^{+}\right]_{0} \exp \left(\frac{-\alpha F}{R T}\left(E-E_{f}^{\Theta}\right)\right)
$$


where $k_{\mathrm{ox}}$ and $k_{\text {red }}$ are the apparent rates of electron transfer for the oxidation and reduction processes respectively. $\beta$ and $\alpha$ refer to the transfer coefficients of the oxidation and reduction respectively $\beta+\alpha=1$.

Both $k_{\mathrm{ox}}$ and $k_{\text {red }}$ can be described by the Frumkin corrections:

$$
\begin{aligned}
& k_{\mathrm{ox}}=k^{0} \exp \left(\frac{-\left(z_{\mathrm{M}}+\beta\right) F}{R T}\left(\phi(x)-\phi_{s}\right)\right) \\
& k_{\text {red }}=k^{0} \exp \left(\frac{\left(\alpha-z_{\mathrm{M}(\mathrm{I})}\right) F}{R T}\left(\phi(x)-\phi_{s}\right)\right)
\end{aligned}
$$

where $\left(\phi(x)-\phi_{S}\right)$ can be described by the GCS model as previously discussed. In this model, $k^{0}\left(\mathrm{~s}^{-1}\right)$ takes the same value for both oxidation and reduction processes. Therefore, $k_{\mathrm{ox}}=k_{\text {red }}$ under the condition that $\beta+\alpha=1$.

Including the effect of extended electron transfer, the oxidative flux can be described by the following:

$$
j=\int_{0}^{\infty}\left\{k_{\mathrm{ox}}[]^{\Theta} \exp \left(\frac{\beta F}{R T}\left(E-E_{f}^{\Theta}\right)\right)-k_{\mathrm{red}}\left[\mathrm{M}^{+}\right]_{0} \exp \left(\frac{-\alpha F}{R T}\left(E-E_{f}^{\Theta}\right)\right)\right\} \mathrm{d} x
$$

By combining equations 5 and 23, we get:

$$
\frac{D}{\delta}\left[\mathrm{M}^{n+}\right]_{0}=\int_{0}^{\infty}\left\{k_{\mathrm{ox}}[]^{\Theta} \exp \left(\frac{\beta F}{R T}\left(E-E_{f}^{\Theta}\right)\right)-k_{\mathrm{red}}\left[\mathrm{M}^{+}\right]_{0} \exp \left(\frac{-\alpha F}{R T}\left(E-E_{f}^{\Theta}\right)\right)\right\} \mathrm{d} x
$$

Equation 24 can be rearranged to yield the expression for the concentration of $\mathrm{M}^{+}$at the electrode surface: 


$$
\left[\mathrm{M}^{+}\right]_{0}=\frac{[]^{\Theta} \exp \left(\frac{\beta F}{R T}\left(E-E_{f}^{\Theta}\right)\right) \int_{0}^{\infty} k_{\text {ox }} \mathrm{d} x}{\frac{D}{\delta}+\exp \left(\frac{-\alpha F}{R T}\left(E-E_{f}^{\Theta}\right)\right) \int_{0}^{\infty} k_{\text {red }} \mathrm{d} x}
$$

By substituting the values of $\left[\mathrm{M}^{+}\right]_{0}$ back into equation 23 , the stripping voltammetry can be predicted. Figure 6 presents the resulting simulated voltammograms for the set of parameters given in Table 1 for different concentrations of electrolytes. The results show that in this model, the rates of electron transfer for the forward (oxidation) and backward (reduction) reactions relative to that of mass transport now influence both the position and the shape of the voltammetry.

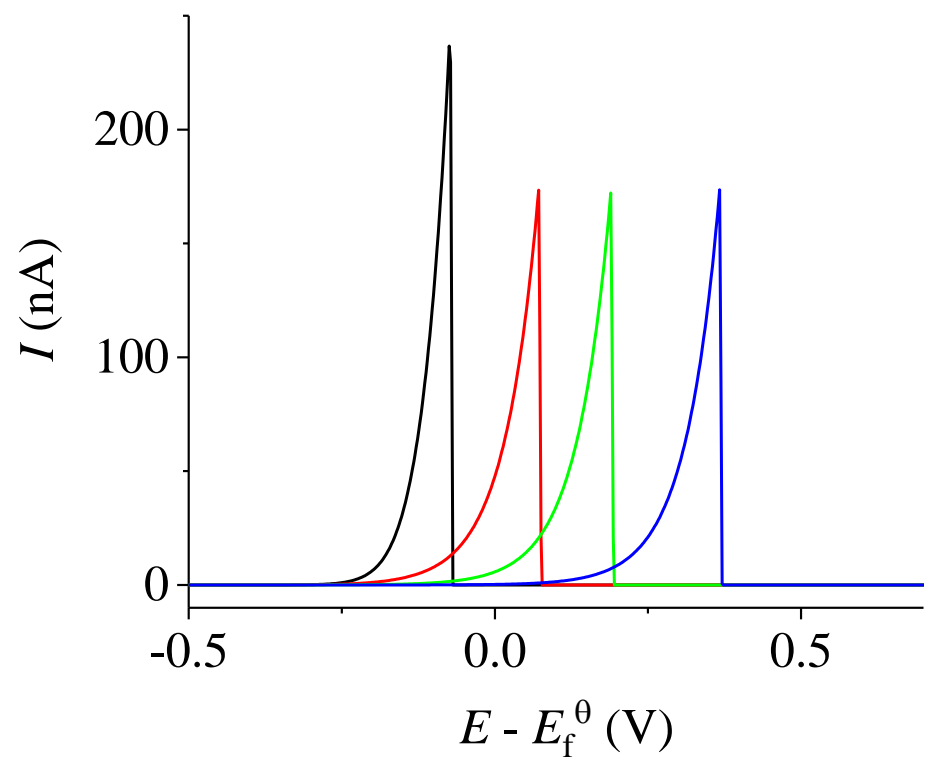

Figure 6: Theoretically predicted anodic stripping voltammetry of a one-electron metal oxidation in a quasi-reversible limit with extended electron transfer in different concentrations of 1:1 electrolytes: (black) $100 \mathrm{mM}$, (red) $100 \mu \mathrm{M}$, (green) $1 \mu \mathrm{M}$ and (blue) $1 \mathrm{nM}$. Scan rate of $20 \mathrm{mV} \mathrm{s}^{-1} \cdot Q_{\max }=500$ $\mathrm{nC}, k^{\prime}=1 \times 10^{8} \mathrm{~s}^{-1}, \beta=0.5, E_{f}^{\Theta}=0.5 \mathrm{~V}, \phi_{\mathrm{pzc}}=0 \mathrm{~V}, D=1 \times 10^{-9} \mathrm{~m}^{2} \mathrm{~s}^{-1}$.

\subsection{Ohmic drop for stripping voltammetry at a microdisc electrode}


In addition to the electron transfer kinetics, the voltammetric responses can also be affected by the electrical resistance of electrolyte solutions. The effects of uncompensated resistance or Ohmic drop on the distortion of voltammograms for a surface-bound and a diffusional redox process have been previously demonstrated by Feldberg ${ }^{14}$ and Dickinson et al. ${ }^{11}$ respectively. In the stripping voltammetry studied herein, a similar distortion of the voltammograms is expected as the resistance of the solution increases with decreasing electrolyte concentrations.

At a sufficiently small disc electrode, the ohmic drop $\left(I R_{\text {ohmic }}\right)$ can be approximated as occurring only in the vicinity of the electrode. ${ }^{23}$ According to the formula derived by Newman ${ }^{23}$ as described briefly in the Introduction, the static ohmic resistance of the solution may be determined from its conductivity by: ${ }^{23}$

$$
R_{\mathrm{ohmic}}=\frac{1}{4 \kappa r_{\mathrm{e}}}
$$

where $\kappa$ is the electrical conductivity of the solution and $r_{\mathrm{e}}$ is the radius of the disc electrode. At steady-state, the resistances could be different from the static resistances described above by a factor of $\frac{D_{\text {cation }}+D_{\text {anion }}}{2 D_{\mathrm{M}^{+}}}$, where $D$ is the diffusion coefficient, $\mathrm{M}^{+}$is the oxidation product, cation and anion refer to the constituents of the supporting electrolytes. ${ }^{32}$

The potential $(E)$ is thus corrected for the uncompensated resistance to:

$$
E=E_{\mathrm{app}}-I R_{\mathrm{ohmic}}
$$

where $E_{\mathrm{app}}$ is the potential applied at the working electrode relative to the reference electrode. $I$ is the current passed during the measurement. 
Figure 7 compares the theoretically predicted anodic stripping voltammetric responses of a one-electron metal oxidation in a reversible electron transfer limit (fast electrode kinetics) at a microdisc electrode for the parameters given in the caption of the figure and a range of

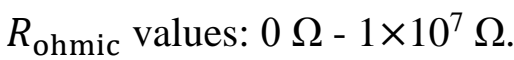

At $100 \mathrm{mM}$, the voltammetric response at a microdisc electrode is not altered from that predicted for the zero resistance solution, due to the sufficiently high electrolyte concentrations and hence the low solution resistance. At lower concentrations, the large resistance now contributes significantly to the voltammetric responses. The stripping peaks occur at higher potentials and become significantly distorted as the oxidation requires higher overpotentials.

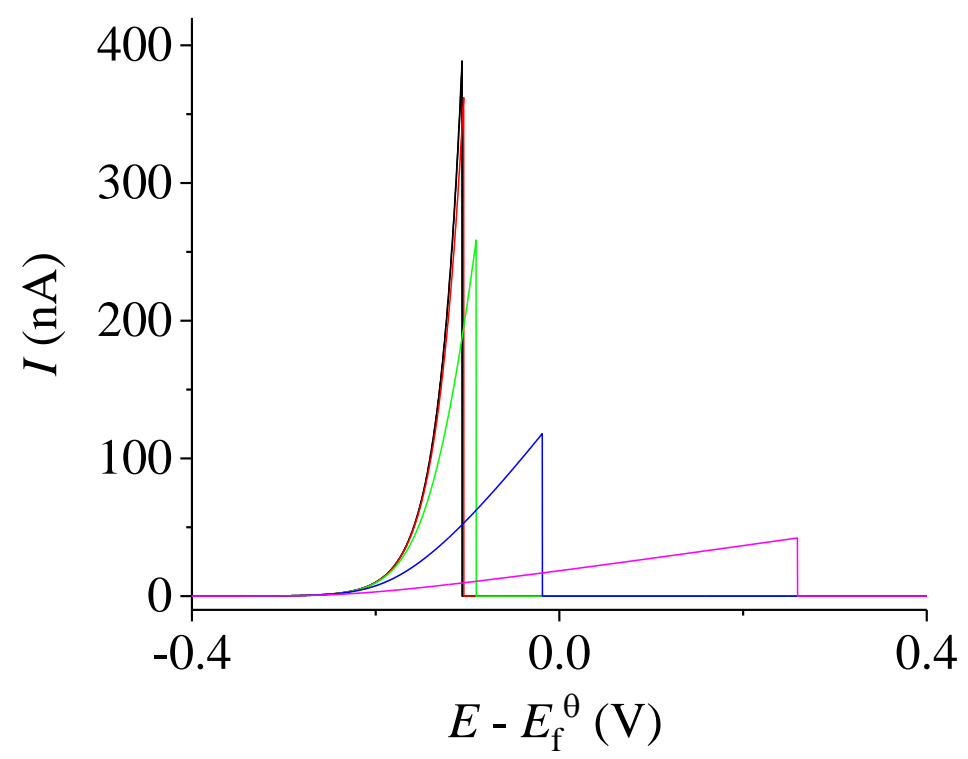

Figure 7: Theoretically predicted anodic stripping voltammetry of a one-electron metal oxidation in a reversible electron transfer limit (fast electrode kinetics) at a range of $R_{\text {ohmic }}$ values: (black, two graphs superimpose) $0 \Omega$ and $1 \times 10^{3} \Omega$, (red) $1 \times 10^{4} \Omega$, (green) $1 \times 10^{5} \Omega$, (blue) $1 \times 10^{6} \Omega$ and (pink) $1 \times 10^{7} \Omega$. Scan rate of $20 \mathrm{mV} \mathrm{s}^{-1} \cdot Q_{\max }=500 \mathrm{nC}$. $E_{f}^{\Theta}=0.5 \mathrm{~V}, D=1 \times 10^{-9} \mathrm{~m}^{2} \mathrm{~s}^{-1}$. 


\subsection{Combined kinetic and ohmic drop effects for stripping voltammetry at a microdisc electrode}

To study the contribution of both the double-layer kinetics and the ohmic drop effects to the voltammetric responses, we combine the quasi-reversible electron transfer model (including the effects of the back reaction and the extended electron transfer, section 2.3) with the ohmic drop model (section 2.4). In particular, the potential term $(E)$ in the Butler-Volmer kinetics in equation 20 is corrected by the ohmic drop ( $E=E_{\text {app }}-I R_{\text {ohmic }}$, equation 27$)$. The stripping voltammetric response is then calculated as described in section 2.3. This model will be used to describe and compare with the experimental results.

An iterative method is needed to solve the ohmic drop model. In this work, numerical calculation of the voltammetric responses was performed using scripts written in Python 3.5.2 in the Enthought Canopy package (Enthought, TX, USA).

\section{Experimental}

\subsection{Chemical reagents and instrumentation}

Silver nitrate $\left(\mathrm{AgNO}_{3}, \geq 99.0 \%\right)$ and potassium nitrate $\left(\mathrm{KNO}_{3}, \geq 99.0 \%\right)$ were obtained from Sigma-Aldrich UK and used as received without further purification. Solutions were prepared using deionised water (Millipore) with the resistivity as measured inside the Millipore filtration system of $18.2 \mathrm{M} \Omega \mathrm{cm}$.

Note the conductivity of deionized water $\left(25^{\circ} \mathrm{C}\right)$ is $0.055 \mu \mathrm{S} \mathrm{cm}^{-1}$ (resistivity $18.2 \mathrm{M} \Omega \mathrm{cm}$ ) inside the filtration system, however, within ca. 10s of seconds the conductivity will rise to $1.33 \mu \mathrm{S} \mathrm{cm}{ }^{-1}{ }^{27}$ This change in conductivity arises due to the hydration of dissolved carbon dioxide in the solution. To decrease the conductivity in the electrochemical cell, the water is 
further treated with ion exchange (IEx) resin beads (MR-450 UPW) obtained from Dowex according to the procedures reported by $\mathrm{Li}$ et al. ${ }^{27}$ to yield and maintain 'ultra-low conductivity water.'

All electrochemical experiments were performed with a $\mu$ Autolab Type III potentiostat (Utrecht) using a standard three electrode setup in a Faraday cage thermostated at $25^{\circ} \mathrm{C}$. A platinum microdisc $(64.9 \mu \mathrm{m}$ radius, homemade as previously described and characterised elsewhere ${ }^{33}$ ) was used as a working electrode. A platinum mesh was used as a counter electrode. A leakless $\mathrm{Ag} / \mathrm{AgCl}$ (in $3.4 \mathrm{M} \mathrm{KCl}$, eDAQ) or a $\mathrm{Ag}$ wire was employed as a reference electrode.

The choice of the reference electrode is chosen such that the effects of ionic contamination on the measured voltammetric responses is minimized for the different electrolytes studied. To obtain well-defined electrode potentials, a proper reference electrode (with known concentrations of reference redox species) is required. To minimize contamination of chloride ions, silver ions and the leakage of any other ionic species into the solutions, a leakless $\mathrm{Ag} / \mathrm{AgCl}[3.4 \mathrm{M} \mathrm{KCl}]$ (eDAQ, Australia) is first used as a reference electrode. Even the 'leakless' electrode however is found to significantly increase the conductivity of deionized water by a factor of $\sim 2$. To maintain low electrolyte concentrations, a silver wire is thus used as a pseudo reference electrode for measurements in deionized water and ultra-low conductivity water. The potential difference between a silver wire and the leakless $\mathrm{Ag} / \mathrm{AgCl}$ $[3.4 \mathrm{M} \mathrm{KCl}]$ is $0.31 \pm 0.05 \mathrm{~V}$, see Section S2, SI. Throughout the rest of this work, the potentials are all presented as 'vs. leakless $\mathrm{RE}$ (vs. $\mathrm{Ag} / \mathrm{AgCl}[3.4 \mathrm{M} \mathrm{KCl}]$ )' for the ease of comparison. We further highlight that in the absence of excess supporting electrolyte the junction potential with the reference electrode may lead to a non-insignificant shift in the potential scale. 


\subsection{Methods}

\subsubsection{Electrochemical measurements}

First, silver is deposited onto the surface of the electrode immersed in the solution of $200 \mu \mathrm{M}$

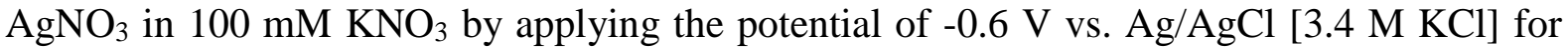
$60 \mathrm{~s}$. The deposition may not be uniform as a result of convergent diffusion to a microdisc electrode. The pre-deposited electrode is then subjected to anodic stripping voltammetry ( $E$ $=-0.6 \mathrm{~V} \rightarrow 0.8 \mathrm{~V}$, scan rate of $20 \mathrm{mV} \mathrm{s}^{-1}$ ) either in the same solution or after transferred to fresh solutions of $200 \mu \mathrm{M} \mathrm{AgNO}_{3}$, deionized water and ultra-low conductivity water. All solutions were deoxygenated by strong, continuous flow of nitrogen gas for 5 min prior to voltammetric measurements.

\subsubsection{Conductivity measurements}

The electrical conductivities of the solutions were measured using a 2-pole probe (InLab 742, Mettler Toledo) connected to a conductivity portable meter kit (Seven2Go S3, Mettler Toledo).

\section{$4 \quad$ Results and discussion}

With the aim of studying the effects of electrolyte concentration on the silver stripping process, a microdisc electrode $(62.5 \mu \mathrm{m}$ radius) deposited with $5.2 \mathrm{pmol}$ of silver (equivalent to $\sim 500 \mathrm{nC})$ is subjected to anodic stripping voltammetry in electrolytes of different concentrations. This amount of silver corresponds to multilayers with the average thickness of $\sim 4.3 \mathrm{~nm}$. 
We first consider the anodic responses in $100 \mathrm{mM} \mathrm{KNO}_{3}$, where the system can be considered to be 'fully-supported,' as presented in Figure 8. A sharp anodic stripping peak is observed at $0.41 \mathrm{~V}$, earlier than its formal potential $\left(E_{f}^{\Theta}=0.53 \mathrm{~V}\right.$ vs. $\mathrm{Ag} / \mathrm{AgCl}[3.4 \mathrm{M}$ $\mathrm{KCl}]^{1}$ ). This is due to the finite amount of silver on the surface and the mass transport of $\mathrm{Ag}^{+}$ (aq) away from the electrode, in agreement with previous work. ${ }^{1}$

To describe the observed voltammetry, the reversible model (Section 2.1) is first considered. The formal potential $\left(E_{f}^{\Theta}=0.53 \mathrm{~V}\right)^{1}$ and diffusion coefficient $\left(D=1.2 \times 10^{-9} \mathrm{~m}^{2} \mathrm{~s}^{-1}\right)^{2}$ given in Table 1 are used. All the parameters are the reported experimental values of this redox system and no fitting parameter is used in this model. Figure 8 compares the simulated and experimental anodic stripping voltammetry of silver in $\sim 100 \mathrm{mM}$ electrolyte. A good fit between the theoretical and experimental data is observed. This implies that at the concentration of $100 \mathrm{mM}$ the electrode kinetics of silver oxidation is significantly faster than the mass transport of $\mathrm{Ag}^{+}$away from the microdisc electrode $(62.5 \mu \mathrm{m}$ radius $)$. The simulated voltammetry however shows much sharper and higher peak than the experimental result. This discrepancy arises due to breakdown in the assumption of electrode being uniform and the energetics of monolayer i.e. silver on platinum will differ from that of silver on silver. Furthermore, the model assumes that a steady-state mass-transport regime is operative. For the given electrode size, the time required to reach a steady-state mass-transport regime will be approximately of the order of 2 seconds, at this experimental scan rate the voltammetric stripping of the silver occurs over the course of approximately 8 seconds; consequently, the assumption of steady-state mass-transport is questionable. However, we highlight the good agreement between experimental and theory at least partially validates the assumptions made within the development of the theoretical model. 


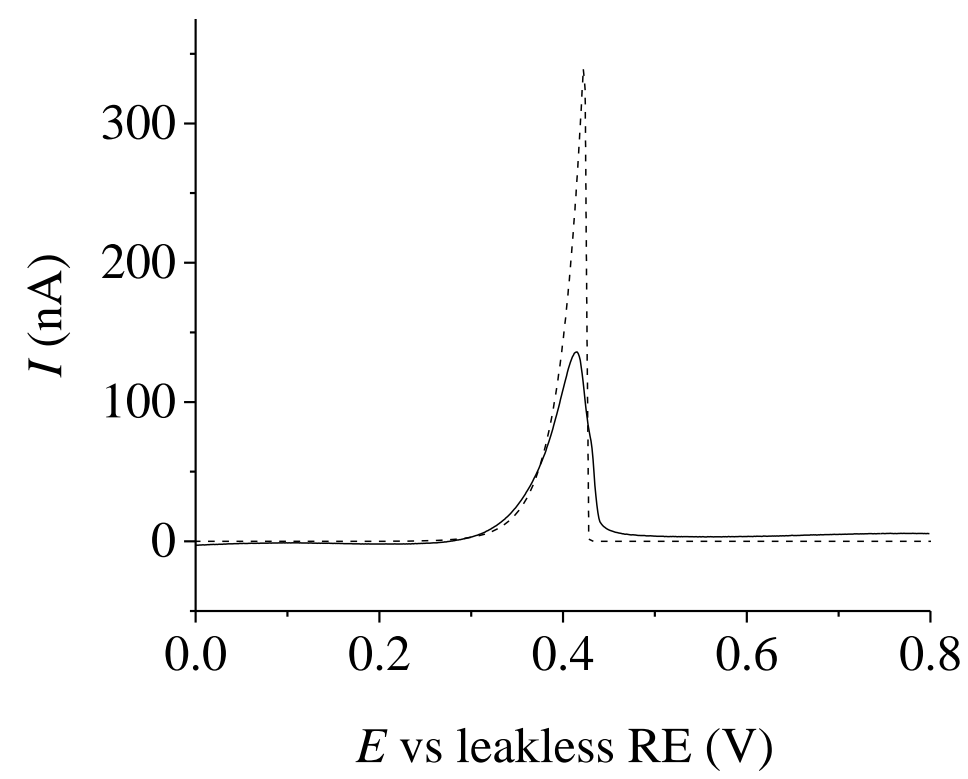

Figure 8: Comparison of experimental and theoretically predicted (reversible model) anodic stripping voltammetry of pre-deposited $5.2 \times 10^{-12}$ mol of silver at a platinum microdisc electrode $(62.5 \mu \mathrm{m}$ radius) in $200 \mu \mathrm{M} \mathrm{AgNO}_{3}$ in $100 \mathrm{mM} \mathrm{KNO}_{3}$ at the scan rate of $20 \mathrm{mV} \mathrm{s}^{-1}$.

A range of lower electrolyte concentrations are next investigated. Experimentally, it is not possible to completely remove electrolytes from the solutions. Deionized water is not entirely free from electrolytes and inevitably contains as an absolute minimum $\sim 0.1 \mu \mathrm{M} \mathrm{H}^{+}$and $\mathrm{OH}^{-}$. However, due to the presence of dissolved gas e.g. carbon dioxide, such low conductivities are rarely maintained for more than a few seconds. Purging a solution with nitrogen is incapable of the complete removal of the dissolved gas as evidenced by measuring the resulting deionized solution conductivity $\left(0.36 \pm 0.01 \mu \mathrm{S} \mathrm{cm}^{-1}\right.$, corresponding to the ionic strength of $1.82 \pm 0.05 \mu \mathrm{M}) .{ }^{27}$ Lower concentrations of ionic species can, however, be achieved and maintained by further treatment of the water with ion exchange (IEx) resin beads $^{27}$ to yield the solution conductivity of $0.080 \pm 0.001 \mu \mathrm{S} \mathrm{cm}^{-1}$, corresponding to the total ion concentrations of $360 \pm 5 \mathrm{nM}$, see procedures in the Experimental section. We call this 'ultra-low conductivity water.' 
The solid lines in Figure 9 depict the experimentally recorded voltammograms. The stripping peaks occur at higher potentials: $0.51 \mathrm{~V}, 0.78 \mathrm{~V}$ and $1.07 \mathrm{~V}$ in $200 \mu \mathrm{M}, 1.8 \mu \mathrm{M}$ (deionized water) and $360 \mathrm{nM}$ (ultra-low conductivity water) electrolytes respectively. This set of results demonstrates that the oxidation of surface-deposited silver can take place at a microdisc electrode ( $\mathrm{Pt}, 62.5 \mu \mathrm{m}$ radius) even in the near absence of electrolyte. For all the electrolyte concentrations studied, $82 \pm 14 \%$ of the deposited silver is oxidized. The incomplete stripping is potentially due to the loss of the material from the surface. ${ }^{34}$ The total charge transferred during the entire stripping process is not altered by varying concentrations of supporting electrolytes. However, the shapes of the voltammograms appear heavily distorted as the electrolyte concentration is lowered.

This distortion cannot be explained by the reversible model, described in section 2.1. The irreversible (section 2.2) and quasi-reversible (section 2.3) kinetic models are also demonstrated (results presented in sections S3.2-S3.3 in the SI) to be able to account for only $<50 \%$ of the distortion in terms of the stripping peak potentials. The underestimation of the voltammetric distortion predicted using Frumkin correction may reflect the reversible (fast electron transfer) nature of silver oxidation, where the voltammetric responses more likely reflect the solution-phase mass transport. We have nonetheless demonstrated the possible outcome of the alteration in the electrode kinetics upon lowering electrolyte concentrations. Compared to the change in the electron transfer kinetics, ohmic drop (section 2.4) contributes much more significantly to the voltammetric distortion, both the shift in the peak potential and the shape of the voltammetry, refer to section S3.4 in the SI. Herein, both the kinetic effects (quasi-reversible model) and the ohmic drop are considered simultaneously, the combined model of which has been previously introduced in section 2.5. 
Figure 9 presents the experimental results compared with the voltammograms simulated using the following parameters: $E_{f}^{\Theta}=0.53 \mathrm{~V}, \beta=0.5, k^{\prime}=8.0 \times 10^{8} \mathrm{~s}^{-1}$, and the values of resistances discussed next. At $100 \mathrm{mM}\left(R_{\text {ohmic }}=3.7 \times 10^{3} \Omega\right)$ and $200 \mu \mathrm{M}\left(R_{\text {ohmic }}=6.1 \times\right.$ $10^{5} \Omega$ ), the resistances predicted by eqn. 26 give excellent fit with the experimental data, see Table 2 and Figure 9. However for $1.8 \mu \mathrm{M}$ and $360 \mathrm{nM}$ electrolytes, the resistances that give the best fit between the experimental and the theoretical responses are $5.0 \times 10^{6} \Omega$ and $2.0 \times 10^{7} \Omega$, factors of 20 and 25 smaller than predicted by eqn. 26 respectively, see Table 2 .

From these results, we have showed that the semi-analytical approach based on the quasireversible Frumkin kinetics and the ohmic drop developed in this work can essentially model the distortion in shape and the positive shift in the peak potentials of silver anodic stripping voltammetry under low support conditions. The discrepancy in the values of resistances at very low electrolyte concentrations may arise due to the assumptions made in the derivation of eqn. 26 such as the resistance being concentrated at a point and/or the limitations of the experiments. In particular, the measurement of the solution electrical conductivity can only be done in the bulk solution and not directly in the double-layer region.

In addition to anodic stripping, we further demonstrate that the deposition of silver can also take place in the absence of added supporting electrolytes, allowing electroanalytical detection of silver ions under low support conditions and further demonstrating the advantages of a microelectrode, see section 3.6 in the SI. 


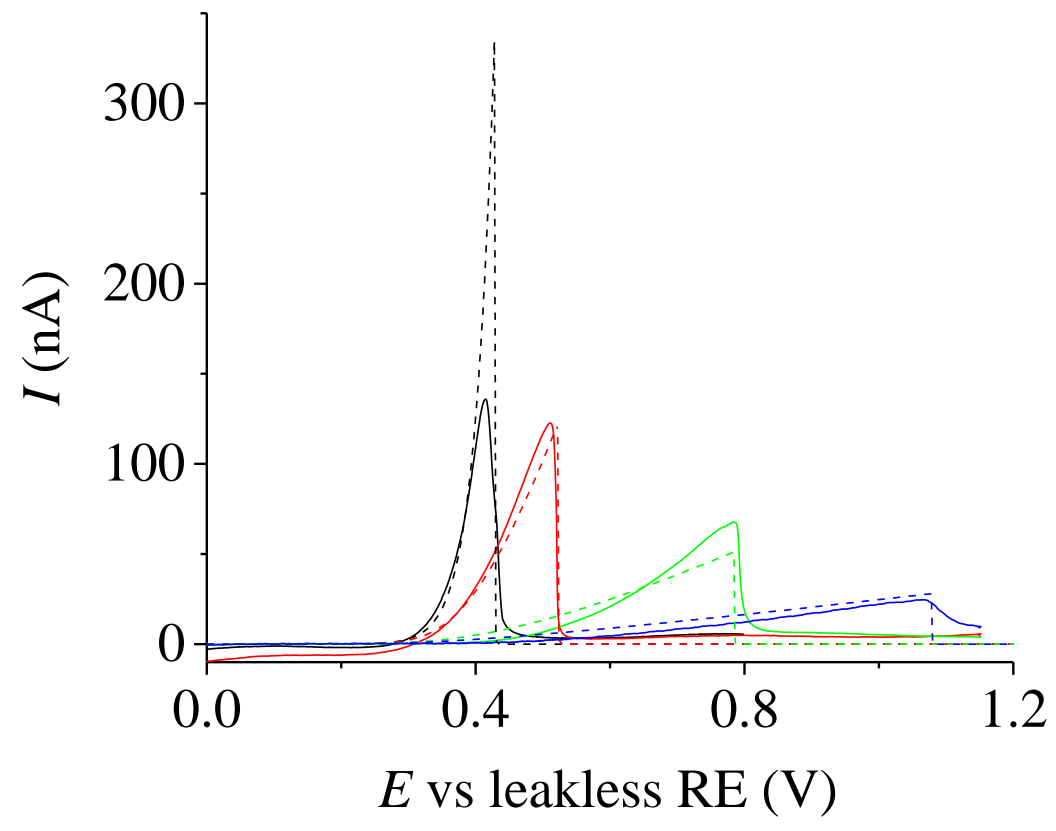

Figure 9: Comparison of experimental (solid lines) and theoretically predicted (dashed lines) anodic stripping voltammetry of pre-deposited $5.2 \times 10^{-12} \mathrm{~mol}$ of silver at a platinum microdisc electrode

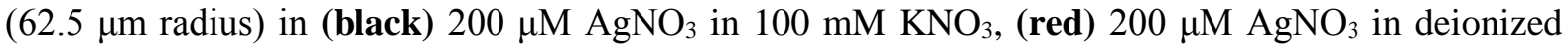
water, (green) deionized water $(1.8 \mu \mathrm{M})$ and (blue) ultra-low conductivity water $(360 \mathrm{nM})$ at the scan rate of $20 \mathrm{mV} \mathrm{s}^{-1}$. The theoretical model used herein is the combined quasi-reversible kinetics (with extended electron transfer) and ohmic drop model: $k^{\prime}=4 \times 10^{8} \mathrm{~s}^{-1}, \beta=0.5, E_{f}^{\Theta}=0.53 \mathrm{~V}, \phi_{\mathrm{pzc}}$ $=-0.6 \mathrm{~V}$.

Table 1: Physical constants used in this work.

\begin{tabular}{|l|l|}
\hline \multicolumn{1}{|c|}{ Physical Parameter } & \multicolumn{1}{c|}{ Value } \\
\hline Diffusion coefficient of $\mathrm{Ag}^{+}$ & $1.2 \times 10^{-9} \mathrm{~m}^{2} \mathrm{~s}^{-12}$ \\
\hline Formal potential of $\mathrm{Ag}=\mathrm{Ag}^{+}+\mathrm{e}^{-}$ & $0.53 \mathrm{~V}\left(\mathrm{vs} . \mathrm{Ag} / \mathrm{AgCl} / \mathrm{Cl}^{-}[3.4 \mathrm{M} \mathrm{KCl}]\right)^{1}$ \\
\hline Atomic mass of silver & $107.9 \mathrm{~g} \mathrm{~mol}^{-1}$ \\
\hline Density of silver & $10.5 \times 10^{6} \mathrm{~g} \mathrm{~m}^{-3}$ \\
\hline Electrode radius (Pt microdisc) & $62.5 \times 10^{-6} \mathrm{~m}$ \\
\hline Tunnelling coefficient, $\beta_{\mathrm{t}}$ & $1.59 \times 10^{10} \mathrm{~m}{\text { (water })^{31}}$ \\
\hline
\end{tabular}


Table 2: Measured electrical conductivities, estimated electrolyte concentrations, the predicted resistances (using eqn. 26) and the values of resistances best-fit with experimental data (Figure 9).

\begin{tabular}{|c|c|c|c|c|}
\hline & $\begin{array}{c}\text { Measured } \\
\text { Conductivity, } \mathrm{S} \mathrm{m}^{-1}\end{array}$ & Ionic strengths & $\begin{array}{l}\text { Resistance } \\
\text { (eqn. 26), } \Omega\end{array}$ & $\begin{array}{l}\text { Resistance } \\
\text { best fit, } \Omega\end{array}$ \\
\hline $\begin{array}{l}200 \mu \mathrm{M} \mathrm{AgNO}_{3} \text { in } \\
100 \mathrm{mM} \mathrm{KNO}_{3}\end{array}$ & 1.1 & $100.2 \mathrm{mM}$ & $3.7 \times 10^{3}$ & $3.7 \times 10^{3}$ \\
\hline $200 \mu \mathrm{M} \mathrm{AgNO} 3$ & $6.6 \times 10^{-3}$ & $200 \mu \mathrm{M}$ & $6.1 \times 10^{5}$ & $6.1 \times 10^{5}$ \\
\hline $\begin{array}{l}\text { Deionized water } \\
\text { (degas) }\end{array}$ & $3.6 \times 10^{-5}$ & $1.8 \mu \mathrm{M}$ & $1.1 \times 10^{8}$ & $5.0 \times 10^{6}$ \\
\hline $\begin{array}{l}\text { Ultra-low } \\
\text { conductivity water }\end{array}$ & $8.0 \times 10^{-6}$ & $360 \mathrm{nM}$ & $5.0 \times 10^{8}$ & $2.0 \times 10^{7}$ \\
\hline
\end{tabular}

\section{Conclusions}

Silver oxidation can take place at a microdisc electrode in the absence of added supporting electrolyte, and although the resulting voltammetry is distorted as the electrolyte concentration is lowered, the total stripping charge is not affected. This paper further illustrates, using the silver oxidation, that a Frumkin-type correction cannot fully explain the distortion in anodic stripping voltammetry upon the lowering of electrolyte concentrations. In fact, it only contributes maximally to $\sim 50 \%$ of the distortion, suggesting that the alteration in the voltammetric shape and position do not solely arise from the double-layer kinetics. The ohmic drop (calculated on the basis of Newman's constriction resistance), on the other hand, is shown to overestimate the extent of voltammetric distortion, suggesting either the inaccurate assumption of the Newman model and/or the limitation of the conductivity measurements. By altering the values of the solution resistances, the developed semianalytical model combining of the double-layer kinetics and the ohmic drop shows a good fit with experimental results. Overall, this paper demonstrates the potential applications of silver 
detection in the absence of electrolytes, as well as presents the theoretical model to explain the experimentally observed anodic stripping voltammetry.

\section{Acknowledgements}

KN receives funding from the Royal Thai government (DPST scholarship). This project is supported by the funding from the European Research Council under the European Union's Seventh Framework Programme (FP/2007-2013)/ERC Grant Agreement no. [320403].

\section{References}

1. Toh, H. S.; Batchelor-McAuley, C.; Tschulik, K.; Uhlemann, M.; Crossley, A.; Compton, R. G., The anodic stripping voltammetry of nanoparticles: electrochemical evidence for the surface agglomeration of silver nanoparticles. Nanoscale 2013, 5 (11), 4884-93.

2. Ward Jones, S. E.; Campbell, F. W.; Baron, R.; Xiao, L.; Compton, R. G., Particle Size and Surface Coverage Effects in the Stripping Voltammetry of Silver Nanoparticles: Theory and Experiment. J. Phys. Chem. C 2008, 112 (46), 17820-17827.

3. Batley, G. E., Electroanalytical techniques for the determination of heavy metals in seawater. Mar. Chem. 1983, 12 (2-3), 107-117.

4. Wang, J.; Lu, J.; Hocevar, S. B.; Farias, P. A. M.; Ogorevc, B., Bismuth-Coated Carbon Electrodes for Anodic Stripping Voltammetry. Anal. Chem. 2000, 72 (14), 3218-3222.

5. Dai, X.; Nekrassova, O.; Hyde, M. E.; Compton, R. G., Anodic stripping voltammetry of arsenic(III) using gold nanoparticle-modified electrodes. Anal. Chem. 2004, 76 (19), 5924-9.

6. Batley, G.; Florence, T., An evaluation and comparison of some techniques of anodic stripping voltammetry. J. Electroanal. Chem. Interfacial Electrochem. 1974, 55 (1), 23-43.

7. Florence, T. M., Anodic stripping voltammetry with a glassy carbon electrode mercury-plated in situ. J. Electroanal. Chem. Interfacial Electrochem. 1970, 27 (2), 273-281.

8. Wehmeyer, K. R.; Wightman, R. M., Cyclic voltammetry and anodic stripping voltammetry with mercury ultramicroelectrodes. Anal. Chem. 2002, 57 (9), 1989-1993.

9. Hoyer, B.; Florence, T. M.; Batley, G. E., Application of polymer-coated glassy carbon electrodes in anodic stripping voltammetry. Anal. Chem. 2002, 59 (13), 1608-1614.

10. Oldham, K. B.; Zoski, C. G., Chapter 2 Mass Transport to Electrodes, in Comprehensive Chemical Kinetics by Bamford, C.H. and Compton, R.G. The Netherlands, 1986, Volume 26. Chapter 2 Mass Transport to Electrodes; in Comprehensive Chemical Kinetics by Bamford, C.H. and Compton, R.G. The Netherlands 1986, 26, 79-143.

11. Dickinson, E. J. F.; Limon-Petersen, J. G.; Rees, N. V.; Compton, R. G., How Much Supporting Electrolyte Is Required to Make a Cyclic Voltammetry Experiment Quantitatively "Diffusional"? A Theoretical and Experimental Investigation. J. Phys. Chem. C 2009, 113 (25), 11157-11171.

12. Clark, R. O. D.; Ngamchuea, K.; Batchelor-McAuley, C.; Compton, R. G., Electrochemical Measurement of the Dissolved Oxygen Concentration in Water in the Absence of Deliberately Added Supporting Electrolyte. Electroanalysis 2017, 29 (5), 1418-1425.

13. Frumkin, A. N., Z. Phys. Chem. Abt. A 1933, 164, 121-133. 
14. Feldberg, S. W., Effect of uncompensated resistance on the cyclic voltammetric response of an electrochemically reversible surface-attached redox couple: Uniform current and potential across the electrode surface. J. Electroanal. Chem. 2008, 624 (1-2), 45-51.

15. Bond, A. M.; Lay, P. A., Cyclic voltammetry at microelectrodes in the absence of added electrolyte using a platinum quasi-reference electrode. J. Electroanal. Chem. Interfacial Electrochem. 1986, 199 (2), 285-295.

16. Bond, A. M.; Fleischmann, M.; Robinson, J., Electrochemistry in organic solvents without supporting electrolyte using platinum microelectrodes. J. Electroanal. Chem. Interfacial Electrochem. 1984, 168 (1-2), 299-312.

17. Ngamchuea, K.; Batchelor-McAuley, C.; Compton, R. G., Understanding electroanalytical measurements in authentic human saliva leading to the detection of salivary uric acid. Sens. Actuators, $B$ 2018, 262, 404-410.

18. Belding, S. R.; Limon-Petersen, J. G.; Dickinson, E. J.; Compton, R. G., Cyclic voltammetry in the absence of excess supporting electrolyte offers extra kinetic and mechanistic insights: comproportionation of anthraquinone and the anthraquinone dianion in acetonitrile. Angew. Chem. 2010, 49 (48), 9242-5.

19. Ciszkowska, M.; Stojek, Z., Voltammetry in solutions of low ionic strength. Electrochemical and analytical aspects. J. Electroanal. Chem. 1999, 466 (2), 129-143.

20. Streeter, I.; Compton, R. G., Numerical Simulation of Potential Step Chronoamperometry at Low Concentrations of Supporting Electrolyte. J. Phys. Chem. C 2008, 112 (35), 13716-13728.

21. Dickinson, E. J. F.; Compton, R. G., Influence of the diffuse double layer on steady-state voltammetry. J. Electroanal. Chem. 2011, 661 (1), 198-212.

22. Limon-Petersen, J. G.; Han, J. T.; Rees, N. V.; Dickinson, E. J. F.; Streeter, I.; Compton, R. G., Quantitative Voltammetry in Weakly Supported Media. Chronoamperometric Studies on Diverse One Electron Redox Couples Containing Various Charged Species: Dissecting Diffusional and Migrational Contributions and Assessing the Breakdown of Electroneutrality. J. Phys. Chem. C 2010, 114 (5), 2227-2236.

23. Newman, J., Resistance for Flow of Current to a Disk. J. Electrochem. Soc. 1966, 113 (5), 501.

24. Bento, F. M.; Thouin, L.; Amatore, C., Potential measurements in steady state voltammetry at low electrolyte/analyte concentration ratios. Role of convection on ohmic drop: A simplified model. Journal of Electroanalytical Chemistry 1998, 446 (1-2), 91-105.

25. Lang, N.; Kohn, W., Theory of metal surfaces: charge density and surface energy. Phys. Rev. $B$ 1970, 1 (12), 4555 .

26. Albery, J., Electrode kinetics. Clarendon Press, Oxford: 1975.

27. Li, X.; Batchelor-McAuley, C.; Laborda, E.; Compton, R. G., Aqueous Voltammetry in the Near Absence of Electrolyte. Chem. Eur. J. 2017, 23 (60), 15222-15226.

28. Gavaghan, D. J.; Feldberg, S. W., Extended electron transfer and the Frumkin correction. $J$. Electroanal. Chem. 2000, 491 (1-2), 103-110.

29. Wang, H.; Pilon, L., Accurate Simulations of Electric Double Layer Capacitance of Ultramicroelectrodes. J. Phys. Chem. C 2011, 115 (33), 16711-16719.

30. Bockris, J. O. M.; Devanathan, M. A. V.; Muller, K., Proc. R. Soc. A 1963, 274, 55-79.

31. Edwards, P. P.; Gray, H. B.; Lodge, M. T.; Williams, R. J., Electron transfer and electronic conduction through an intervening medium. Angew. Chem. 2008, 47 (36), 6758-65.

32. Oldham, K. B., Theory of microelectrode voltammetry with little electrolyte. J. Electroanal. Chem. Interfacial Electrochem. 1988, 250 (1), 1-21.

33. Lin, C.; Jiao, X.; Tschulik, K.; Batchelor-McAuley, C.; Compton, R. G., Influence of Adsorption Kinetics upon the Electrochemically Reversible Hydrogen Oxidation Reaction. J. Phys. Chem. C 2015, 119 (28), 16121-16130.

34. Cloake, S. J.; Toh, H. S.; Lee, P. T.; Salter, C.; Johnston, C.; Compton, R. G., Anodic stripping voltammetry of silver nanoparticles: aggregation leads to incomplete stripping. ChemistryOpen 2015, 4 (1), 22-6. 